\title{
Some Observations on 'Uterine Prolapse' in Western Nepal
}

\author{
--Miss Ruth A. Watson-- \\ M.B. Gh, B., BIRMINGHAM, ENGLAND.
}

As a student the term "Uterine Prolapse" only brought to mind long hours of holding on to retractors, unable to see anything and to most it sounds a dull and uninteresting subject. But over the past 22 years in Nepal I have discovered that this condition causes untold misery to thousands of women and therefore doserves study both of methods of treatment and, if possible, prevention. I did not actually start collecting data until fairly recently but would like to present some facts which have emerged from studying 1500 cases seen in the Shining Hospital, rokhara.

\section{Incidence}

Actual incidence in the child-bearing population is not calculated as we only see a fraction of the people-but it is obviously extremely high. The first factor which was noticenble was an ethnic one.

a! see figure 1

We see many more patients from the Chetri-Brahmin group than any other, but even correcting for this, these people have a much higher incidence. A rather surprising finding is the high incidence among Sunars and yet a low incidence among Newars (Sunars are ethnically of the same group as Newars!.

b) see figure 2

Comparing these patients with a random selection of women attending ou-patients we found that there is no increase in parity of those suffering from uterine prolapse. 
The average number of children borne by those with prolapse being 4.63 and of those without prolapse 4.58 .

c) sec figure 3

This gave, perbaps, the most starting results as they differ radically from those of the text books. Starting with a $10 \%$. onset under 20 years of age showing a decline in onset over the age of 40 years: This age pattern was most strikingly seen in those women who had never borne children.

d) see figure 4

Figure ।

ETHNIC INCIDENCE

\begin{tabular}{|c|c|c|c|}
\hline Group & $\%$ Cases & Correcte & $\%$ \\
\hline Brahmin & $50.53 \%$ & $24.8^{\circ} \%$ & $4586^{\circ}$ \\
\hline Chetri & $2733 \%$ & $21.06 \%$ & \\
\hline Newar & $6.71 \%$ & $5.46 \%$ & \\
\hline Damai & $1.82 \%$ & $4.73 \%$ & \\
\hline Gurung & $4.12 \%$ & $4.68 \%$ & \\
\hline Sunar & $4.60 \%$ & $27.45 \%$ & \\
\hline Muslim & $0.95 \%$ & $1.06 \%$ & \\
\hline Maggar & $0.67 \%$ & $0.46 \%$ & \\
\hline Thakurini & $0.67 \%$ & $0.09 \%$ & \\
\hline Karmi & $0.86 \%$ & $7.02 \%$ & \\
\hline Sarki & $1.53 \%$ & $1.87 \%$ & \\
\hline Lamini & $0.095 \%$ & $0.25 \%$ & \\
\hline Gyni & $0.095 \%$ & $0.25 \%$ & \\
\hline
\end{tabular}



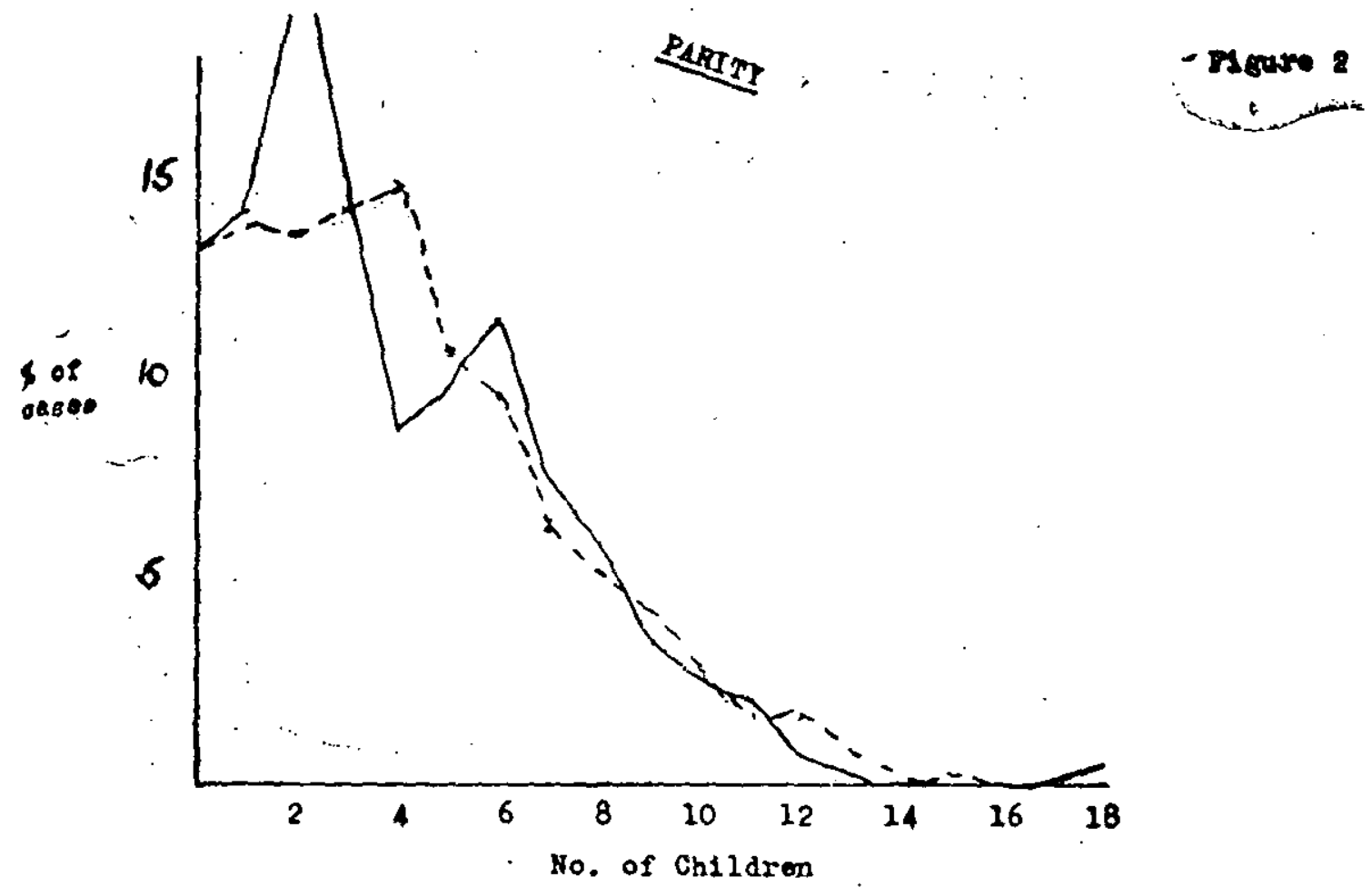

- - Ith prolapao

— Without prolspos

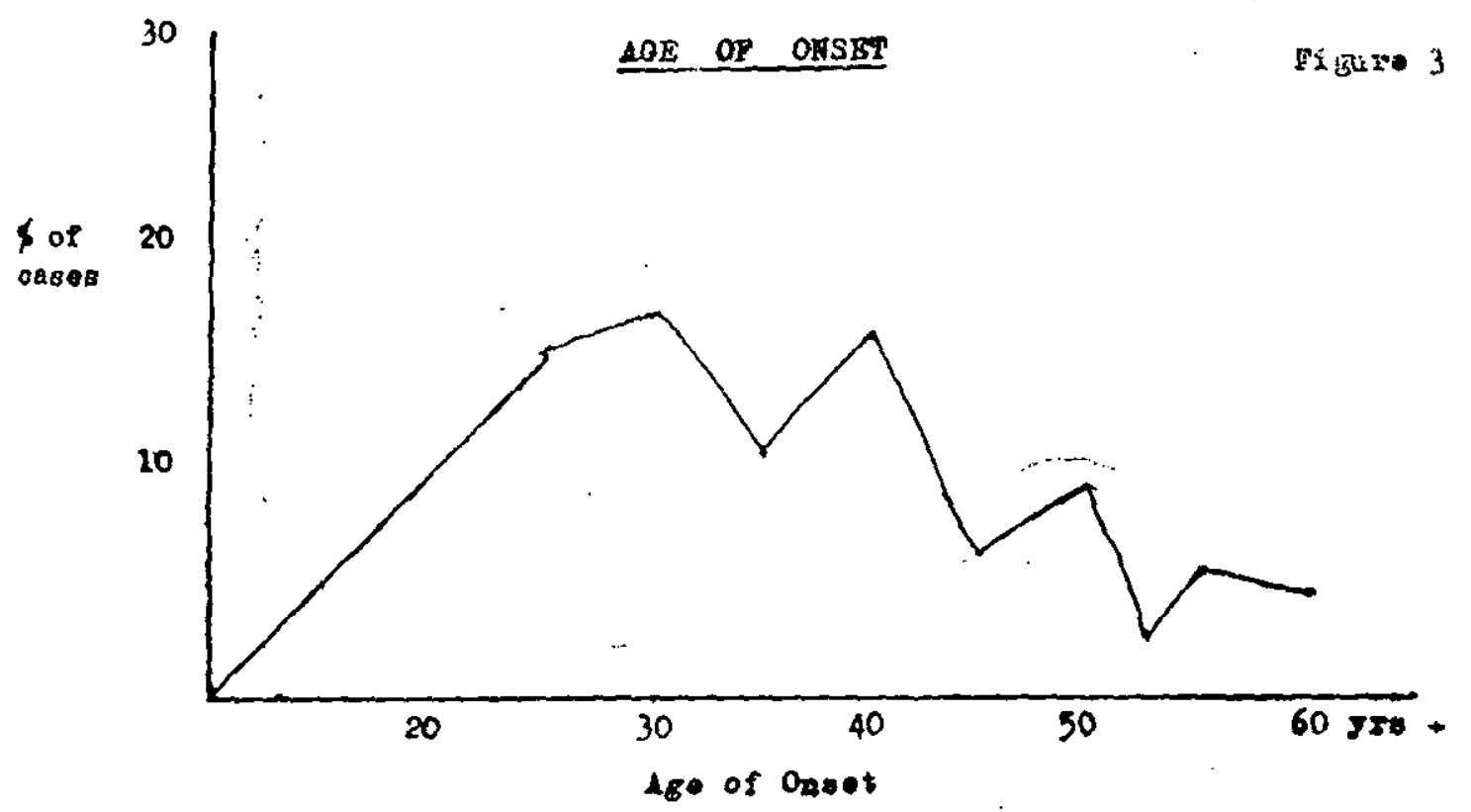


Figure 4

\section{UTERINE PROLAPSE IN NULLIPAROUS WOMEN}
(a) $3.3 \%$ of all cases are nulliparous.
(b) $70 \%$ under 25 years of age.
(c) $88.9 \%$ Chhetri-Brahmin.

\section{Causation}

Nearly $100 \%$ of these cases presented as 2 nd and 3rd degiee untrine prolapse - i.e. uterıne descent with cervix or complete uterus being outside the vulva. Vaginal prolapse without uterine descent is uncommon and stress incontience rarely complained of. Many cases presented with decubital ulceration of the cervix.

The accepted theory of causation is a congenital or developmental weakness of the supports of the uterus, these being mainly the utero-sacral and transverse-cervical ligaments. To this is added activating factors such as increased intra-abdominal pressure, obstetric care, general condition of the patient aud type of work. Let us see if our analysis cau shed any light on the importance of these factors.

\section{1) Ethnic Distribution}

Is it merely a weakness in the supports of the uterus in the Chetri-Brabmin group? This may be a factor but the high incidence in the cempletely different group of Sunars challenges the importance of this factor.

\section{2) Obstetric Care}

This includes post-natal care in the home.

(a) No difference in parity suggests this is not an important factor. (Figure 2)

(b) Cultural pattern;; Although Chetri-Brahmin groups have a longer, II day, period of being set aside and usually of complete rest, all groups tend to keep to a pattern of one month off all heavy work.

(c) I have noticed that although the incidence in multiparous women of grossly scarred and split cervices is high it is not these uteri which prolapse. The cervix of a prolapsed uterus is almost always unscarred. It would appear from this that the difficult labour and pushing on an undilated cervix is not an important factor. 


\section{3) General Condition and Work Patterns}

Our cares are drawn from a largely rural area where agricultural work is done mainly by the women. Also, although the making of roads is beginning to change things, many people obtain their living from carrying astonishingly heavy loads.

Certainly the Chetri-Brahmin women work very hard in the fielde and on the whole their diet is poor dus largely to cultural restrictions in type of food. Protein is low. Sunars do not have these restrictions but in the rural areas their livelibood is insecure and periodic. I discovered that both groups have a similar dietary deficiency in that they quite often have to go for a day or two with very little food, then eat a very large meal. This irregularity in eating habits may be a factor in other common conditions in Nepal-for instance mid-gut rotation, a volvulus of the whole of the small gut, often seen in a similar ethnic pattern.

Sunars do not, as a rule, do heavy manual work while Tamangi carry the heaviest loads of any people I know and yet we have not seen a case of uterine prolapse in this group. This tends to discount the work factor.

\section{4) Raised Intra-Abdominal Pressure}

This may be due to several reasons.

(a) Chronic constipation.

This is uncommon in rutal people of Nepal due to the high roughage content of their diet.

(b) Chronis cough.

This is extremely common but follows no ethnic pattern and of course increases with age and would not explain the early onset.

(c) Cultural patterns of clothing.

The Patuka is an essential part of dress of nearly all rural women in Nepal. It consists of several yards of material wound around the lower half of the trunk and it acts both as a support and a shoppins basket, But there are different ways of wearing this garment. Here in the valley the Japus wear it evenly wound from symphysis to epigastrium, while the Chetri-Brahmin of our area wear theirs drawn as tigtt as possible around the waist. After childbirth one of the first actions is to pull the Patuka as tight as possible to "prevent the blood going up". I have actually seen skin ulceration from these Patukas 
and many have a skin discolouration from the repeated trauma of a tight binder. Could this be a factor? I would like to know of other's experience in other parts of Nepal before suggesting a change in National dress!-but in the meantime perhaps these factors should be borne in mind when preparing our A.N.M's for work in rural areas.

\section{Treatment}

Such a widespread condition needs a simple remedy that can be used in all areas saftly. Operation with anterior and posterior colporrhaphy and amputation of cervix with tightening of the transverse cervical ligaments is the treatment of choice but in most cascs is impractical. If future fregnancies ensue the patient has to be hospitalised for delivery and so oftèn in this series the prolapse occurred after the first child or even before any delivery. The size of this problem too makes operation the treatment practical for only a very small percentage. The solid ring pessary is safe and simple if changed regularly. This can be dode by the A.N.M. in Health Posts and so treatment could be made available to a latge majority of women:

\section{Complications}

(a) lacerations from falling astride stones or when carrying bunciles of wood;

(b) Malignaricy. This is rare but more common than after pessary treatment. Many women do fail to attend for change regularly but apart from an offensive discharge I have seen no permanent damage and no malignancy in 22 years.

(c) Stone formation in the bladder is quite common and very distressing.

(d) Strangulation during pregnancy. This can produce a severe toxic illness and much distress and even be fatal.

(e) I have known a pessary cause a retained placenta on several occasions. The hard foetal head pushing past the pessary but the soft placenta being held up.

\section{In Conclusion}

An analysis of 1500 cases of uterine prolapse seen in Woitern Nepal-bring to light some interesting factors in the probable causation or activation of this condition. A strong ethnic incidence is noted, while parity has little influence. The very early onsef, $10 \%$ before the age of 20 years, is strikingly unusual. Some tentative reasons for this variation from the pattern in other places are put forward. One of these being dietary, 
the other the effect of raised intra-abdominal pressure caused by a tight Patuka or binder. These two factors often work together as to asuage the pangs of hunger the woman will increase the pressure of her Patuka.

Finally, may I give a simple word of belp to any of you who will be practising in remote areas. Uterine prolapse in buffaloes is a fatal condition. It can easily be controlled by reduction (with the buffalo securely fastened on its side) and a deck quoit fastened on externally by a three-pronged string harness - I keep a deck quoit handy for this emergency! 